\title{
Autologous-Cell Leukemia Vaccine
}

National Cancer Institute

\section{Source}

National Cancer Institute. Autologous-Cell Leukemia Vaccine. NCI Thesaurus. Code C2023.

An autologous therapeutic vaccine for the treatment of acute myelogenous leukemia.

This vaccine is prepared from blood samples of patients following their first relapse.

Tumor cells extracted from blood sample are modified with hapten, a process that makes the cells appear foreign to the patient's body and results in stimulating immune response against the cancer. 